\title{
Design and Simulations of Load Management Impact on Power System
}

\author{
S. Joshi ${ }^{{ }^{*}}$ and D.K. Rai ${ }^{2}$ \\ ${ }^{1 *}$ Dept. of Electrical and Electronics SVCE, RGPV Indore (M.P.) India \\ ${ }^{2}$ Dept. of Electrical Department SVCE, RGPV Indore (M.P.) India \\ *Corresponding Author: shubhjoshi.93@gmail.com
}

Available online at: www.isroset.org

Received: 22/Nov/2017, Revised: 05/Dec/2017, Accepted: 20//Dec/2017, Published: 31/Dec/2017

\begin{abstract}
The growth in the demand for electricity in India during the last decade witnessed a dramatic growth in the national's annual residential development has played a major role in boosting the demand for electric power. The domestic sector in India already accounts for approximately 39 percent of electricity demand. To meet the projected demand for electrical power to cope with, the development plans, increases in the population and the rising in the living standards, government will have to accomplish new power generating units. Comparing with the high budget of constructing new generating power units, load management system it would be attractive resource that should be seriously considered as an important part of national energy program, where demand growth rate exceeds the supply since it is playing an increasing role around the world as a valuable and cost-effective energy resource. Hence, was light projecting on power load management program, for its benefit in reducing the energy demand at peak time?.
\end{abstract}

Keywords: Load Management, Maximum Demand, Demand Factor, Tariffs, Load Shifting, Load Reduction.

\section{INTRODUCTION}

Electricity is characterized by the fact that its production and consumption act nearly at the same time. Furthermore electricity cannot be stored in large quantities. This means that power generation must match demand alteration, whereas demand is affected by climate, economic growth and customers' consumption patterns. These factors make the demand to fluctuate at different time. Utility must invest in the generation plant and equipment to keep enough net peaking capability according to the system maximum demand. If the utilities do not impose any system measures, there will be a serious imbalance in power supply and demand. Excessive or insufficient investment will lead to idle asset or create power shortage problems that will be uncomfortable to both suppliers and customers. The system is referred to the "Demand Side Management". Demand side management is the effective, efficient and economic use of energy by an organization. It relates to all forms of energy; electricity, gas, solar, diesel, petrol etc.

Definition: "Load management, also known as demand side management (DSM), is the process of balancing the supply of electricity on the network with the electrical

Load by adjusting or controlling the load rather than the power station output".

This can be achieved by direct intervention of the utility in real time, by the use of frequency sensitive relays triggering the circuit breakers (ripple control), by time clocks, or by using special tariffs to influence consumer behavior. Load management allows utilities to reduce demand for electricity during peak usage times ("peak shaving"), which can, in turn, reduce costs by eliminating the need for peak power plants.

\section{CONCEPT OF POWER LOAD MANAGEMENT}

The load management is a new concept of distribution of electricity aiming at a more efficacious supply network system. Such a control system should satisfy the needs of consumers at the lowest possible peak loading. There is a strong upward tendency in using load management throughout the world. The direct load management systems have passed through the experimental stage and have been now adapted as an everyday practice is a great many of supply network systems. The economic grounds for introduction of these systems have been justified throughout the world and also certain. The load management is a process going along with electricity conservation which decreases total electricity consumption, while the load management is intended for consumption control over a certain period of time.

Load management is defined "as sets of objectives designed to control and modifies the patterns of demands of various consumers of a power utility. This control and modification enables the supply system to meet the demand at all times in most economic manner." 


\section{TRANSMISSION AND DISTRIBUTION LINES:}

The power plants typically produce 50 cycle/second (Hertz), alternating-current (AC) electricity with voltages between $11 \mathrm{kV}$ and $33 \mathrm{kV}$. At the power plant site, the 3 -phase voltage is stepped up to a higher voltage for transmission on cables strung on cross-country towers. High voltage (HV) and extra high voltage (EHV) transmission is the next stage from power plant to Tran's port A.C. power over long distances at voltages like; $220 \mathrm{kV} \& 400 \mathrm{kV}$.

\section{POWER LOAD MANAGEMENT - SUPPLY AND DEMAND:}

Load management does not aim to decrease the overall electricity consumption, rather approaches (or replies to) the consumption pattern. It could be applied both on energy demand and on supply sides

\section{Supply-Side Load Management}

This management is defined as the measure, which is taken at the supply side to meet the demand. The concept has been very popular in the seventies of the twentieth century. If the society demanded more power, the power companies would simply find a way to supply users even by building more generation facilities. This was the essence of the concept.

\section{Demand-Side of Power Load Management}

This management describes the planning and implementation of activities designed to influence customers in such a way that the shape of the power load curve of the utility can be modified to produce power in an optimal way. Peak clipping and load shifting from peak to off-peak period's techniques are used to achieve these purposes. Demand side load management includes not only technical or economic but social measures as well, since it is directly related to the behavioural issues.

\section{METHODS OF IMPLEMENTATION OF POWER MANAGEMENT}

A variety of statistical and artificial intelligence techniques have been developed and used for short-term load forecasting. Although several techniques have been developed, there is no single technique that can satisfy all the needs of the utilities. This is because of the fact that utility service areas vary in differing combinations of commercial, residential and industrial customers. They also vary in geographic, climatologic and economic characteristics. One of the most common techniques used for load forecasting is the time series method. Time series methods have been used as a forecast method for a long time now in various fields like load forecasting, economics and digital signal processing. This method is based on the assumption that the data have an internal structure, such as autocorrelation, trend or seasonal variation. The most often used time series methods are autoregressive moving average (ARMA), Auto-regressive integrated moving average (ARIMA), Auto-regressive moving average with exogenous variables (ARMAX) and auto-regressive integrated moving average with exogenous variables. While ARMA models are usually used for stationary processes, ARIMA models are used for nonstationary processes. However, both RMA and ARIMA which is just an extension of ARMA) use load and time as their own inputs. This chapter deals with the basic concepts underlying the general stochastic models and gives a step-bystep approach to modeling loads, considering effects of weather.

The electricity consumption can be controlled in two ways:

1) Direct Control Load Management (DLC).

2) Indirect Control Load Management (IDLC).

\section{Direct Control Load Management (DLC)}

Direct load management is achieved by the utility directly disconnecting, reconnecting, or modifying the operation of the end-use electric devices. LM implementation requires additional equipment installed on the consumer site for controlling demand.

Loads can be interrupted either by the utility, through a remotely activated signals or locally at the consumer premises. Utility remote control produces more predictable results and involves the use of a communication system. Local control involves the voluntary use of time clocks by consumers to alter their equipment usage in response to price signals or incentives.

Weather sensitive loads are the targets of direct load control, of which air-conditioning $(\mathrm{A} / \mathrm{C})$ units and Water heaters (W/H's) were selected for cycling strategy. Although W/H's loads are not large they can influence load changes. Water pumping imposes a major influence on the electric supply system, and their loads have a notable effect on increasing system peak load. A survey of a small sample of A/C unit owners, which was done as part of this work, has shown an increase of electricity consumption in the summer months due to $\mathrm{A} / \mathrm{C}$ load. An average of 8 hours/day of $\mathrm{A} / \mathrm{C}$ units in service was recorded including peak hours.

\section{Indirect Control Load Management (IDLC)}

Indirect load control is based on economic measures. Different tariffs and pricing mechanisms are introduced in order to encourage customer to optimize load demand. Indirect Control Load Management (IDLC) allows the customers to control their demand independently according to the price signals sent by the utilities serving the energy services.

Usually, a utility's costs vary by time, e.g. by time of day, time of week or time of year. This variation of costs occurs because of the specific situation of the electricity generation 
- production always has to meet demand - and there is no cost-effective way to store electricity. Although production costs vary by time, conventional tariffs are flat tariffs based on average costs that mean they do not reflect the "true" costs of generation. During on-peak periods customers pay the same price for their electricity consumed as at off-peak periods although the generation costs are much higher.

This leads to a cross-subsidization from on-peak periods by off-peak periods. Thus, when electricity prices are based on average costs, customers do not get the correct price signal. This is typically for regulated electricity markets where utilities try to deploy excess capacity. In Figure (6), this problem is sketched: When the electricity price equals the average production costs all types of generation units (base, peak) with corresponding generation costs (Cbase < Cpeak, mc $<$ Cpeak, ac) are needed to meet the demand. But if the electricity price equals the marginal costs of generation, and as a consequence is varying by time, the on-peak demand can be reduced.

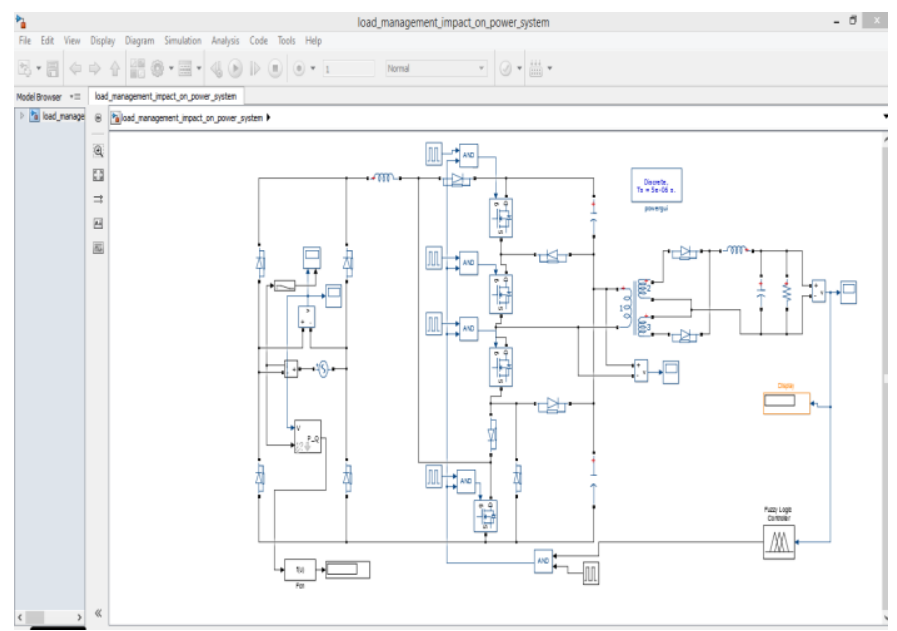

Fig. 1.1 Matlab Simulink model.

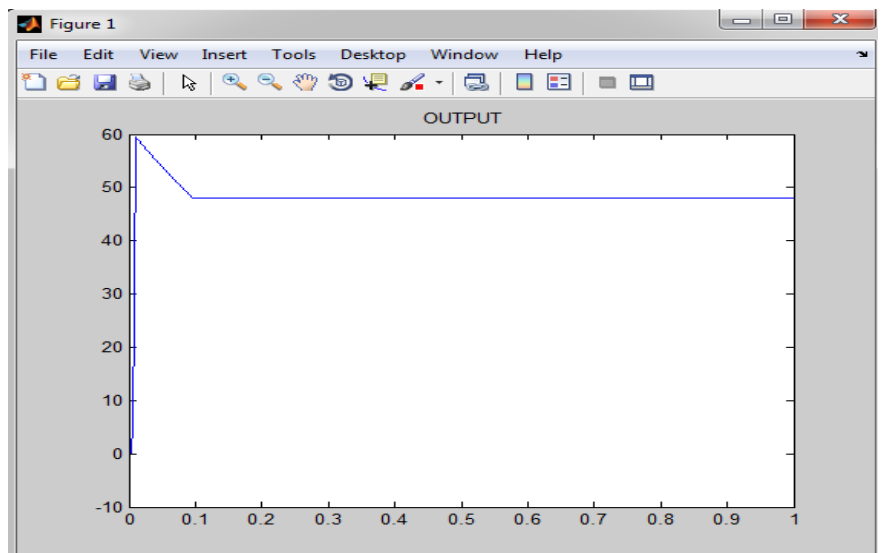

Fig. 1.2 Output of Matlab Simulink model.

\section{CONCLUSION}

The major aim of this work is to forecast one-step-ahead load for individual feeders. The main factor taken into consideration while forecasting these sequences is the weather effect. This work considers three customer classes namely: 1) Residential, 2) Commercial and 3) Industrial. This work gives an insight to topics such as power grid operation, factors affecting forecasting, smart grids, effect of smart grid on load forecasting, real-time pricing and mathematical modelling of load sequences. The major conclusions drawn from this work are as follows:

1. initially, the three sequences, namely residential, commercial and industrial load sequences were found to exhibit non-stationary behaviour. That is they all had time varying mean and variance. Here, effects of temperature on Residential loads were found to be most evident. However, temperature effects on commercial and industrial loads weren't quite evident.

2. after constructing the nominal load sequences (ie. removal of the non-stationary component due to weather effects), the residential load sequence was found to become stationary while the commercial and industrial load sequences ill remained non-stationary. This implies that the non-stationary behavior seen in commercial and industrial loads were not due to weather effects. Therefore, while modeling the residential sequence, weather effects have to be considered, given that is has a significant effect on load demand. For commercial and.

Industrial, considering weather effects as a primary factor, might lead to inaccuracies in forecast models. 3. The relationship between the weather induced component of the residential load sequence and temperature was found to be non-linear. It was also found that the weather induced component was found to saturate at higher temperatures.

\section{REFERENCES}

[1] "POWER LOAD MANAGEMENT Techniques and Methods in Electric Power System" Montaser .Atta . kassem1. International Research Journal of Engineering and Technology (IRJET), Volume: 02 Issue: 09| Dec-2015

[2] Abdelfatah Ali Elahwil „Load management implementation, a method of improving financial performance in power system, "IAS"e95 conference record of the 1995 IEEE industry application conference p.2249-54 vol.53.

[3] "Load Management",M.A. Ekhlat, M.M. El-madhoun. S.S. Ben Nasair and M.A. El-Zaidi, Energy and life Journal No. 7.Sept 1996(in Arabic)

[4] [Sorri and Salo, 1992] V.Sorri and T.Salo. Infl uence of the cost control tariffs on the control of electricity consumption in Finland. In Proceedings of DA/DSM ${ }^{\text {ec } 92, J a n u a r y ~} 1992$.

[5] [ Talukdar and Gellings,1987] S. Talukdar and C.w. Gellings. Load Management. IEEE Press. New York, 1987. 
[6] [Wafa,1996] A.R.A Wafa. Optimum load management securing minimum revenue loss in industry. In Proceedings of DA/DSM , 96. Pen Well Conferences and Exhibitions, October 1996.

[7] J. Skeer, "Highlights of the International Energy Agency Conference on Advanced Technologies for Electric Demand-side Management," in Proceeding of Advanced Technologies for Electric Demand-side Management, Sorrento, Italy: International Energy Agency, 1991.

[8] C. W. Gellings, and J. H. Chamberlin, Demand-side Management: Concepts and Methods. Lilburn, Georgia: Fairmont Press, Inc., 1993. 